\title{
The Study of Levofloxacin Effects on Liver Tissue in Wistar Rat
}

\author{
Nazila Vahidi-eyrisofla ${ }^{3^{*}}$, Mehdi Ahmadifar ${ }^{1,2}$, Ali-Mohammad Eini $^{4}$ and Arsalan Kalami ${ }^{5}$ \\ ${ }^{1}$ University of Science and Culture, Faculty of Science, Department of Biology, Tehran, Iran \\ ${ }^{2}$ Department of Embryology at Reproductiv Biomedicine Research Center, Royan Institute for Reproductive Biomedicine, ACECR, Tehran, Iran \\ 3/slamic Azad University, Damghan Branch, Damghan, Iran \\ ${ }^{4}$ Young Researchers Club, Science and Research Branch, Islamic Azad University, Tehran, Iran \\ ${ }^{5}$ Ferdowsi University of Mashhad, Faculty of Veterinary Medicine, Mashhad, Iran
}

*Corresponding author: Nazila Vahidi-eyrisofla, Islamic Azad University, Damghan Branch, Damghan, Iran, E-mail: nazila_vhdi@yahoo.com

Received May 27, 2014, Accepted December 26, 2014, Published December 29, 2014

Copyright: (C) 2015 Vahidi-eyrisofla N, et al. This is an open-access article distributed under the terms of the Creative Commons Attribution License, which permits unrestricted use, distribution, and reproduction in any medium, provided the original author and source are credited.

\begin{abstract}
Introduction and objective: In this study, we examined the effects of the antibiotics levofloxacin on the liver as well as its devastating effects which are ensued from its over-prescription. Levofloxacin serves as one of the antibiotics of genitourinary system and inferior respiratory system. Since liver is the foremost organ that receives all the materials absorbed by intestine through the portal vein, and it is the organ that must neutralize venoms, the toxic effect of most medications on liver manifest itself quicker than other organs.
\end{abstract}

Methodology: For this study, the experiment used 50 male Wistar rats each weighing approximately $250 \pm 15 \mathrm{~g}$. Experiments were conducted. In the first experiment, G1-control, G2-control sham, G3-control plus $0.03 \mathrm{mg} / \mathrm{kg}$, G4control plus $0.06 \mathrm{mg} / \mathrm{kg}$, G5-control plus $0.08 \mathrm{mg} / \mathrm{kg}$ for a 60 days experimental period. The drug was administered orally once a day.

Result: Comparing the enzyme levels of SGOT and SGPT in the treatment, control and sham groups, it represented that there was a rise in the enzyme levels as a result of liver damage caused by taking antibiotics. Observing the microscopic slides of the liver tissue of the treatment group, it suggests sinusoid destruction, the loss of bile ducts, irregular placement of adjacent cells and the absence of Kupffer cells, which in turn confirms the negative effect of levofloxacin on liver tissue.

Conclusion: Like other medications, levofloxacin can exert adversary effects as well as positive effects. Since one of the tissues which are susceptible to this effect is liver, we must bear in mind when it comes to prescribing this medication.

Keywords: Levofloxacin; Genitourinary system; Serum glutamic oxaloacetic transaminase; Serum glutamate-pyruvate transaminase

\section{Introduction}

The liver is the largest organ in the body and placed below the diaphragm and divided into four distinct lobes. The biggest lobe is the right. There are liver cords linked together inside a lobe. The cords are made of liver cells -Hepatocytes; all of them were placed around the central vein in all ray directions. The hepatic sinusoids are covered inside hepatic cords by means of endothelial cells, reticular fibers and the phagocytic von Kupffer cells (Figure 1). They also constitute many lobules of the port area which consists of a branch of the hepatic artery, a branch of portal vein and small bile ducts and probably a lymph duct. Hepatic asini is smaller lobules in relation to supplying blood to hepatic lobules. The terminal branches of the portal vein and the hepatic artery provide blood for asin. Then bile flows into bile duct from asin. Bile canalicular are microscopic canals between adjacent hepatocytes. The bile canalicular collects bile from hepatocytes and transfer it to a network of canalicular in lobules parenchyma; they then discharge it into the bile ducts of the port area.

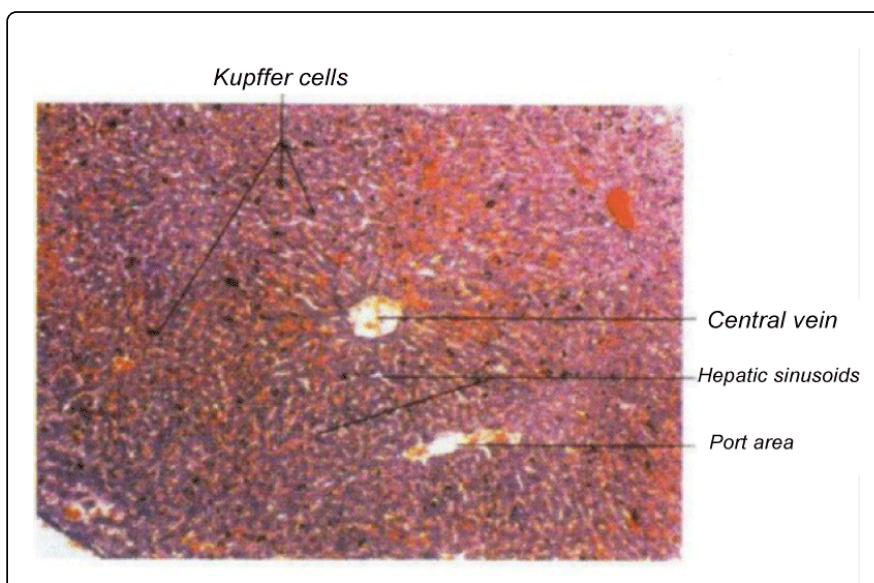

Figure 1: The optical micrograph of a cross-sectioned liver tissue $(\times 100)$. 


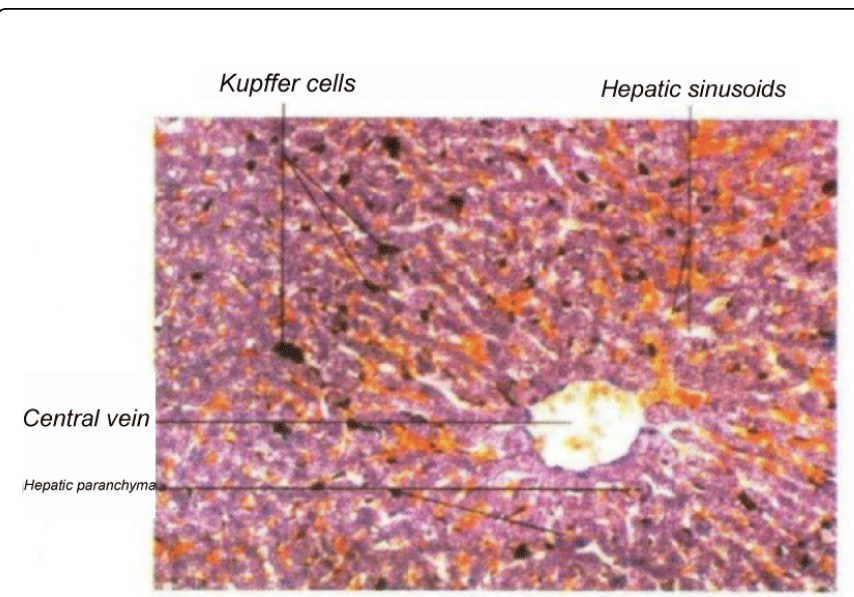

Figure 2: The micrograph represents the order of hepatic parenchyma, where hepatic cells make up wide connecting plains which are generally the thickness of a cell. Moreover, blood cells and Kupffer cells are visible in hepatic sinusoid. The large open space of the central vein can be seen along with endothelial cells $(\times 200)$.

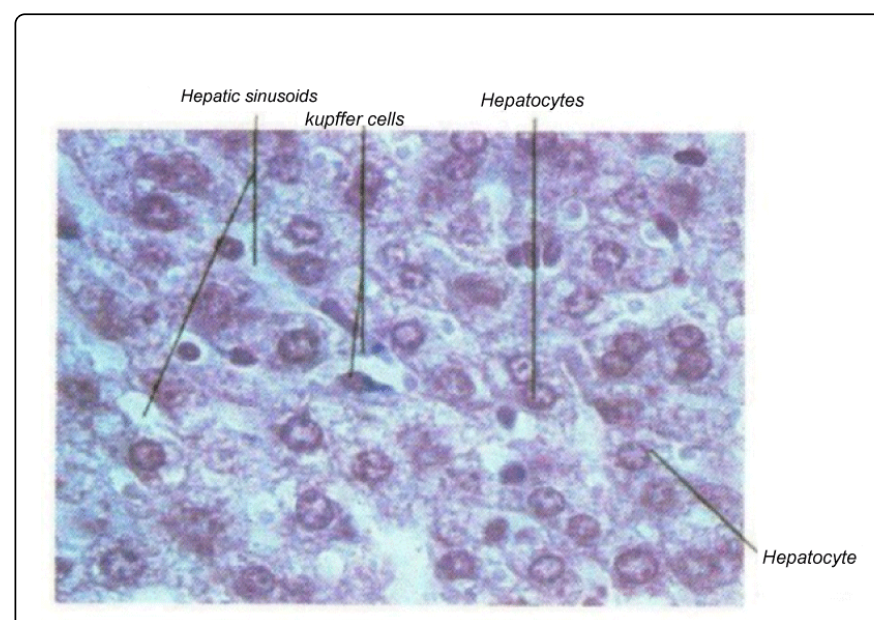

Figure 3: Micrograph of hepatocytes showing large nuclei with peripheral chromatin

The micrograph represents the order of hepatic parenchyma, where hepatic cells make up wide connecting plains which are generally the thickness of a cell (Figure 2). Moreover, blood cells and Kupffer cells are visible in hepatic sinusoid. The large open space of the central vein can be seen along with endothelial cells $(\times 200)$

In the micrograph (Figure 3), hepatocytes can be identified by large nuclei with peripheral chromatin. In general, about $\% 25$ of hepatic cells are nucleated. Other types of existing cells in lobules include: epithelial sinusoid cells which are identifiable by means of dense and wide nucleus and less and visible cytoplasm. Phagocytic Kupffer cells in sinusoids $(\times 1000)$.

One of the biggest and existing troubles is the prevalence of liver diseases and the destruction of the liver tissue. Liver is of the largest interior glands on which chemical, toxins, viruses and parasite can severely inflict damage. In most cases, the pathogenic mechanism remains unknown, which justifies why there are various names for liver disorders. It has been clearly discovered that how liver plays a role in detoxification, protein synthesis as well as storing glycogen and some minerals and vitamins. In order to detect hepatotoxicity caused by levofloxacin, it becomes essential to measure the blood levels of the intracellular enzymes of liver [1]. Among these, SGOT (Pyrvattrans glutamate transaminase) and SGPT (Agzalvastat glutamate transaminase) can be seen in all body cells, particularly in heart, liver, skeleton muscle and kidney cells. As these tissues are hurt under special circumstances, these enzymes will released from damaged cells and their concentration would increase in blood; that is to say, measuring these enzymes can be applied as an index of detecting hepatic damage $[2,3]$.

Liver plays a major role in many essential physiologic processes such as glucose homeostasis, building necessary proteins-plasma, building lipoprotein and lipid, synthesize and secretion of bile acids and vitamins. While the cause of some hepatic diseases remains unknown, oxidizing agents undoubtedly play an important role in the pathological changes in liver particularly in toxic and alcoholic liver [4]. It means that these compounds cause disruption to the membranes cell structure by the peroxidation of biological polyunsaturated fatty acids, leading to pathological changes. In most cases, different inhibitory mechanisms cannot take a full protection; that is why we need supplementary compounds particularly antibiotics [5]. Quinolones are a set of antibiotics with a broad-spectrum treatment which have a good impact on aerobic gram-negative bacteria. However, more recent series of this kind exert strong effect on gram-positive bacteria; their effect mechanism is to inhibit the enzyme of Zhyraz DNA. Theo benzyl and solanul benzyl derivatives 1-3-4, azole tyady which is placed in the carbon number 7 , have antimicrobial effect; theo benzyl 1-3-4 has greater effect of tyody azole. Levofloxacin is of the third-generation antibiotics descended from quinolones which is applied mostly inferior respiratory system, such as pneumonia, chronic lung infections. In addition to this, it is used for curing urine infections as well. As times goes and streptococcus pneumoniae become resistant to penicillin, levofloxacin is indeed good to be prescribed-which is known as Tavanic trademark.

Fluoro quinolone antibiotics, which involve "ciprofloxacin", "levofloxacin", "moksifloxacin", are wide ranging and highly used antibiotics that are prescribed for the treatment of respiratory tract and urine-reproductive tract infections [6]. Previous research indicates that the use of fluoro quinolone antibiotics allows for better functioning in proportion to methroprim-sulfamethoxazole when it comes to bacterial infections caused by gram-negative bacteria with ciprofloxacin and levofloxacin [7]. However, overusing antibiotics inflicts damage to hepatic cells, leading to the destruction of liver tissue. The most widespread effect of abusing antibiotics is to cause antibiotic sensitivity such as skin rash, itching, kidney failure or even serious damage to liver [8]. The activity range of levofloxacin involves a large number of bacterial pathogen species and respiratory system, urinary-reproductive tract, digestive tract and abdominal infections as well as helping to wash away gram-negative bacteria [9]. In general, levofloxacin antibiotics are resistant against bacteria and pathogenic agents, but in rare cases they are manifested as serious and threatening reactions. 
Page 3 of 5

\section{Methodology}

In this study, 50 series of male Wistar rats were used; the rats were eight weeks old and had a weight of about 250 g. During the study which lasted 60 days, the rats were exposed to lightness and then darkness for 12 hours respectively. The room temperature stood at $24.7-26.4^{\circ} \mathrm{C}$ as its moisture was counted as $55-60 \% .30$ series of rats were divided into three groups, receiving the antibiotics with different dilutions; 250, 500 and $750 \mathrm{ml}$; the drug is taken orally. This drug often use in $500 \mathrm{mg}$ does but we choose 3 doses of that one of them lower and one of them higher than usual. That dose is in human but we mixed drug with DW according to the rat weight [10]. 20 series of rats were put in to the two groups control and sham; the first group received treatment as the sham group received water through gavage. After the completion of this round, blood samples were taken from all groups, and dispatched to laboratory for medical diagnosis. The rats were then anesthetized with ether and slit open from the peritoneal area as transverse-abdominal cut, letting the liver out of the body; the samples of the liver tissue were stabilized in $10 \%$ formalin and sent to pathology laboratory for block making and preparing the slides.

\section{Tissue preparation for light microscopic study}

Liver tissue samples were stabilized in $10 \%$ formalin solution. Having the tissues passed and taking blocks in pathology laboratory, microscopic sections with 5 micron thickness were prepared in slides through microtome; after stabilization, staining with HematoxylinEosin was used and coverslip was sealed on it.

\section{Enzyme test practices}

After blood centrifuging, the serum obtained was brought in biochemical auto-analyzer device and hepatic enzyme levels were credited by measuring the level of optical absorption.

\section{Results}

The results were dealt with and the following results were obtained that seem acceptable

\begin{tabular}{|l|l|l|}
\hline Groups/sample & SGOT & SGOPT \\
\hline Control & $43.5 \pm 15$ & $35.75 \pm 9$ \\
\hline control sham & $55 \pm 5$ & $78.25 \pm 5$ \\
\hline Dose $0.03 \mathrm{mg} / \mathrm{kg}$ & $82.37 \pm 32$ & $62.62 \pm 9$ \\
\hline Dose $0.06 \mathrm{mg} / \mathrm{kg}$ & $73.25 \pm 11$ & $64.25 \pm 12$ \\
\hline Dose $0.08 \mathrm{mg} / \mathrm{kg}$ & $63.53 \pm 24$ & $52.71 \pm 14$ \\
\hline
\end{tabular}

Table 1: effect of Levofloxacin on anzymes liver wistar rat (Values are expressed as mean $\pm \mathrm{SE}$ )

Given the results, the following graphs were drawn, indicating that SGOT and SGPT hepatic enzymes escalated as a result of the consumption of the levofloxacin antibiotics in the groups with 250, $500,750 \mathrm{ml}$ in proportion to control and sham groups.

Table 1 indicates SGOT test and a comparison of different groups. The first bar column is control group and the second one is sham, representing quite similar numbers. The other three columns include: under treatment groups with antibiotics with a density of 250, 500, 750 $\mathrm{ml}$ respectively, representing the escalation of SGOT plasma density. Tables 2 and 3 represents SGPT test. The first bar column is control group and the second one is sham which depict quite similar densities. The next three columns are under treatment groups with antibiotics with a density of $250,500,750 \mathrm{ml}$ respectively, representing the escalation of SGPT plasma density.

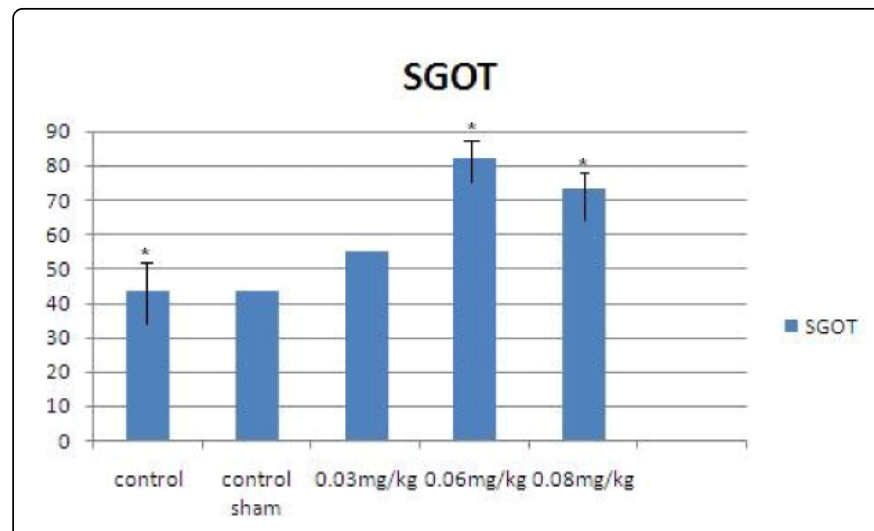

Table 2: The change of SGOT plasma in different groups $(\mathrm{P}>0.05$; Animals were recieved different dose of levofloxacin once time a day (10 AM) for 60 days)

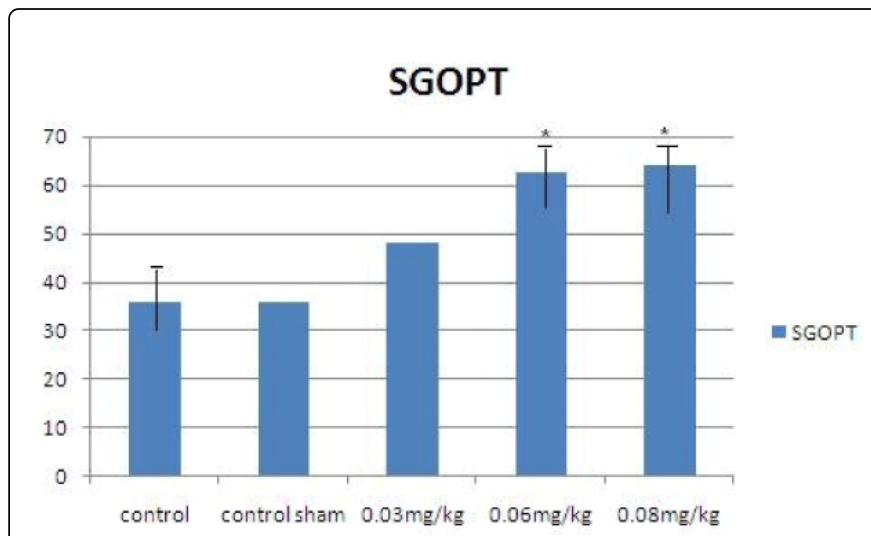

Table 3: The change of SGPT plasma in different groups $(\mathrm{P}>0.05$; Animals were recieved different dose of levofloxacin once time a day (10 AM) for 60 days)

\section{Reviewing the slides obtained from liver tissue revealed the following results}

The Graph 1 taken from liver tissue slide, indicate control group at the magnifications $\times 100$, which represent a fully healthy liver with cells that lie next to each other, eventually there would be bile duct between them and sinusoids and nuclei are clearly visible; it should be noted that sham group is completely the same as control group.

The Graph 2 is taken from the liver tissue slide of the treatment group with antibiotics with $250 \mathrm{mg}$ dose, which represents cell disorganization and their irregular position next to each other and consequently small bile duct can be seen there. 
Citation: Vahidi-eyrisofla N, Ahmadifar M, Eini AM, Kalami A (2015) The Study of Levofloxacin Effects on Liver Tissue in Wistar Rat. J Liver 4:

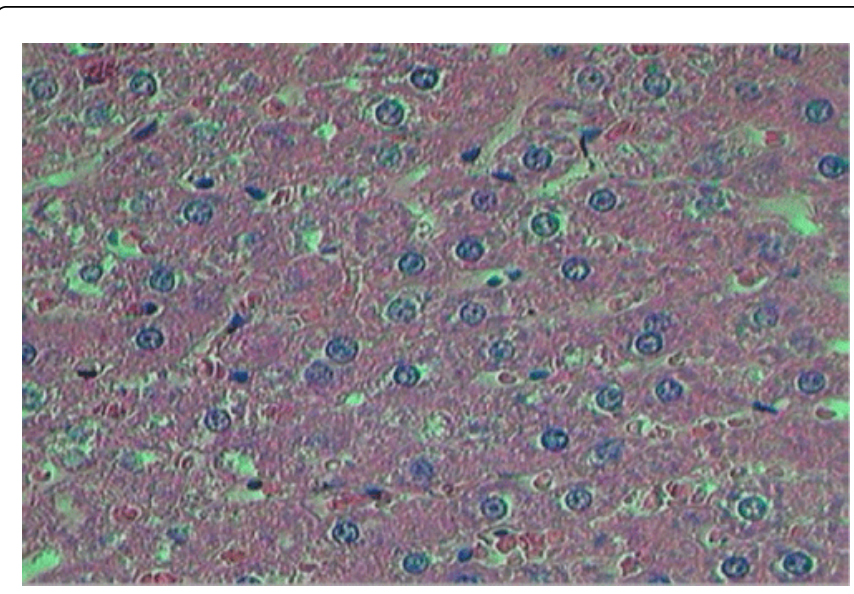

Graph 1: the liver of the control group $\times 100$

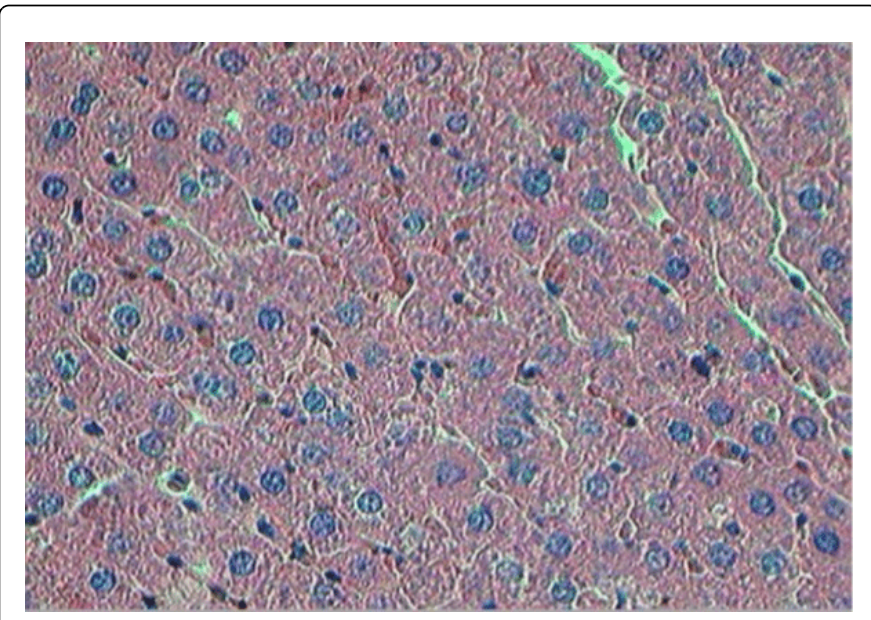

Graph 2: the treatment with 250 dose of levofloxacin x100

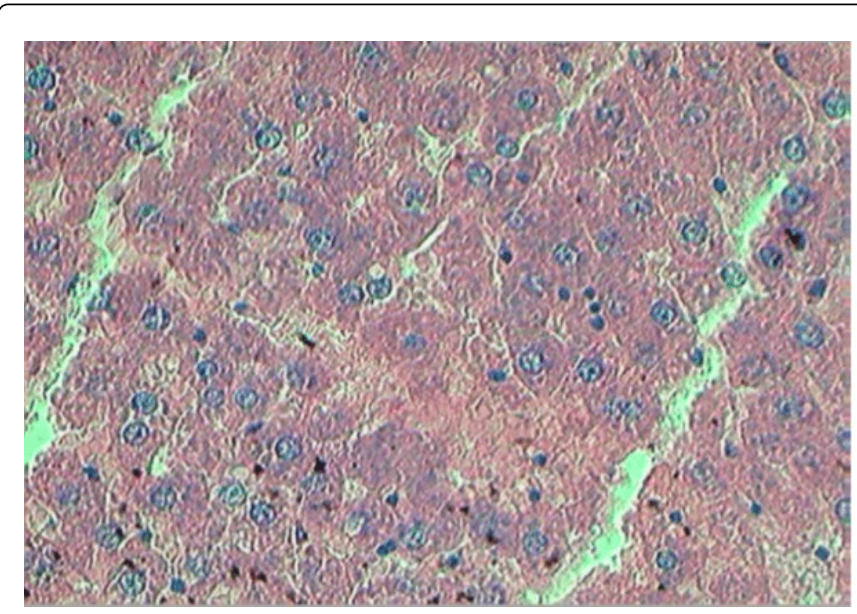

Graph 3: treatment with 500 dose of levofloxacin $\times 100$

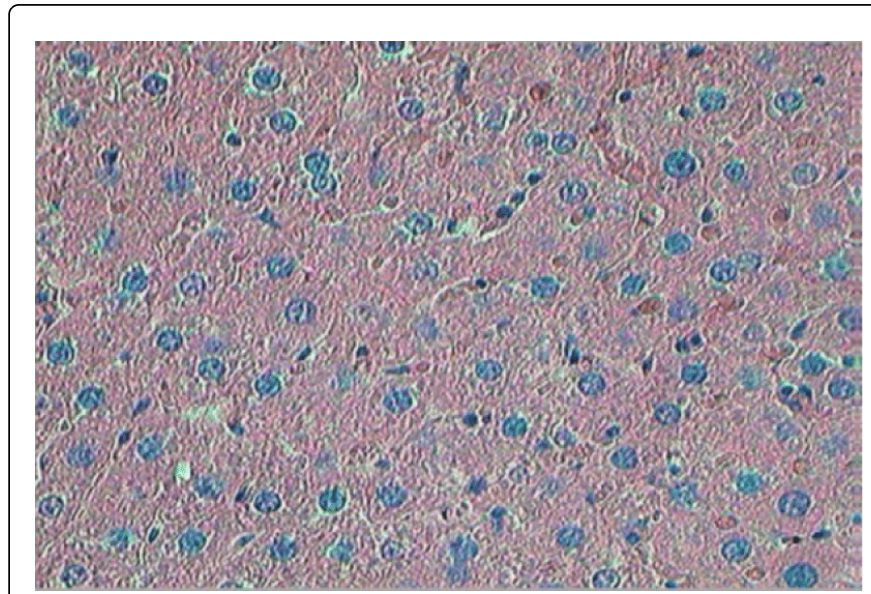

Graph 4: treatment with 750 dose of levofloxacin $\mathrm{mg} / \mathrm{kg} \times 100$

The Graph 3 is taken from the liver tissue slide of the treatmentseen rats that were gavage with $500 \mathrm{mg}$ dose; this indicated that sinusoids were corrupted, cell are placed next to each other as clutter and there is no Kupffer cell.

The Graph 4 is taken from the liver tissue slide of the rats having received medications with $750 \mathrm{mg}$ dose. This represents the destruction of sinusoids as well as bile duct. The cells lay next to each other as clutter and there are no Kupffer cells.

\section{Discussion}

Using medication was observed whether it is typical and nontypical. The foregoing findings were confirmed and reinforced by performing alternative statistical analysis: a dose-response pattern kind was discovered. The threat in question to those who used antipsychotic medics, having not used any medication at the time though, was the same as the one to those who hadn't used medications at all. Moreover, the findings of a propensity analysis which minimizes the effect of destructive potential agents were the same as those of initial analysis. In 2003, National Institute of Health of the United States launched a network of liver medicinal damages [11]. The network is a consortium of five academic medical centers where identify and pursue patients with idiosyncratic hepatotoxicity caused by drugs. In this report, clinical characteristics of 300 primary cases were recorded and presented as summary in this network [12]. Toxicity cases caused by acetaminophen were ruled out from this database. Levofloxacin is normally prescribed for curing respiratory and sinus infections, which may escalates into sever hepatic damage among the elderly [13]. Moreover, many sexually transmitted diseases and infections relate to urinary-reproductive tract and diseases like tuberculosis and brucellosis that require prolonged use of antibiotics for treatment; that is to say, it may be lasted 50 to 70 days and this 50 to-70-days span is in line with the period of spermatogenesis in human and rats $[14,15]$. It is worth mentioning that levofloxacin proved very helpful in curing these chronic infectious diseases [16-18]. In every study in quinolone's family like Ciprofloxacin, Moxifloxacin, Gatifloxacin, Norfloxacin, Ofloxacin and Levofloxacin we can see hepatotoxicity $[9,12,19-23]$. In 2005 levofloxacin in one person who had B type hepatitis cause Acute liver failure [24]. Levofloxacin used up in liver's infection and increased the liver`s enzymes [25]. 
Citation: Vahidi-eyrisofla N, Ahmadifar M, Eini AM, Kalami A (2015) The Study of Levofloxacin Effects on Liver Tissue in Wistar Rat. J Liver 4: 173. doi:10.4172/2167-0889.1000173

Page 5 of 5

\section{Conclusion}

Given the fact that liver counts as a refinery organ in the body and absorbs toxics, we should avoid abusing drugs including levofloxacin which is helpful for the treatment of inferior respiratory and urinary system diseases.

\section{References}

1. Willson JD (1994) Harrisons Principles internal medicine 13 th edition. McGrow-Hill/Inc :1333-1339.

2. Hayes WA (1989) Principle and methods of toxicology ? second edition raves press New York :-12.

3. Sherlac S (1989) Discases of the liver and bilary system 8 edition black Well scientific.Oxford:1-12

4. Androli T, Carpenter C, Griggs R, Benjamin I, (2007) Diseases of the Liver and Biliary System, Cecil'sEssentials of Medicine. 7th ed. USA: WB Saunders Company 23.

5. Luper S (1998) A review of plants used in the treatment of liver disease: part 1. Altern Med Rev 3: 410-421.

6. http://www.khabarfarsi.com/n/5495099

7. GIMEMA Infection Program. (1991) Prevention of bacterial infection in neutropenic patients with hematologic malignancies. A randomized, multicenter trial comparing norfloxacin with ciprofloxacin. The GIMEMA Infection Program. Gruppo Italiano Malattie Ematologiche Maligne dell'Adulto. Ann Intern Med 115: 7-12.

8. http://www.hidoctor.ir/216

9. Brunton L, Lazo J, Parker K (23 August 2005). Goodman \& Gilman's The Pharmacological Basis of Therapeutics. McGraw-Hill Prof Med/Tech. ISBN 978-0-07-142280-2. Retrieved 30 October 2012

10. 3-Akimoto Y, Uda A, Omata H, Shibutani J, Nishimura H, et al. (1990) Cephalexin concentrations in humanserum, gingiva, and mandibular bone following a single oral administration. Gen Pharmacol 21(5): 621-23.

11. Edelman NH, Kaplan RM, Buist AS, Cohen AB, Hoffman LA, et al (1992) Chronic obstructive pulmonary disease. Task Force on Research and Education for the Prevention and Control of Respiratory Diseases. Chest 102: 243S-256S

12. Thakur BS, Jain AK, Sirkar S, Joshi G, Joshi R (2007) Ciprofloxacininduced cholestatic jaundice. Indian J Gastroenterol 26: 51-52.
13. Raz R, Naber KG, Raizenberg C, Rohana Y, Unamba-Oparah I, et al. (2000) Ciprofloxacin $250 \mathrm{mg}$ twice daily versus ofloxacin $200 \mathrm{mg}$ twice daily in the treatment of complicated urinary tract infections in women. Eur J Clin Microbiol Infect Dis 19: 327-331.

14. Hargreaves CA, Rogers S, Hills F, Rahman F, Howell RJ, et al. (1998) Effects of co-trimoxazole, erythromycin, amoxycillin, tetracycline and chloroquine on sperm function in vitro. Hum Reprod 13: 1878-1886.

15. Kerr JB, Maddocks S, Sharpe RM (1992) Testosterone and FSH have independent, synergistic and stage-dependent effects upon spermatogenesis in the rat testis. Cell Tissue Res 268: 179-189.

16. Jun YT, Kim HJ, Song MJ, Lim JH, Lee DG, et al. (2003) In vitro effects of ciprofloxacin and roxithromycin on apoptosis of jurkat $\mathrm{T}$ lymphocytes. Antimicrob Agents Chemother 47: 1161-1164.

17. Giamarellos-Bourboulis EJ, Grecka P, Giamarellou H (1995) Comparative in vitro activity of ciprofloxacin vs 8 antimicrobial agents against nosocomial multiresistant P. aeruginosa strains. Drugs 49 Suppl 2: 203-204.

18. Norra C, Skobel E, Breuer C, Haase G, Hanrath P, et al. (2003) Ciprofloxacin-induced acute psychosis in a patient with multidrugresistant tuberculosis. Eur Psychiatry 18: 262-263.

19. Bhagirath MK (2009) "A Case Report of Highly Suspected CiprofloxacinInduced Hepatotoxicity," Turkey Journal of Gastroenterology 3: 204-206.

20. Direct Healthcare Professional Communication Regard-ing Moxifloxacin $\left(\right.$ Avelox $\left.{ }^{\circ}\right)$ and Serious Hepatic and Bullous Skin Reactions. Bayer HealthCare Medical In-formation Department, (Medicines and Healthcare Prod-ucts Regulatory Agency (MHRA), Bayer). www.yeuowcard.gov.ukh

21. Henann NE, Zambie MF "Gatifloxacin-Associ- ated Acute Hepatitis," Pharmacotherapy 2: 1579-1582.

22. Blum A (1991) Ofloxacin-induced acute severe hepatitis. South Med J 84: 1158.

23. Xiao L, Sheng C (2010) "Anaphylactic Shock with Liver Damage Caused by Levofloxacin Injection," Chinese Journal of Drug Application and Monitoring 7: 32 .

24. Coban S, Ceydilek B, Ekiz F, Erden E, Soykan I (2005) Levofloxacininduced acute fulminant hepatic failure in a patient with chronic hepatitis B infection. Ann Pharmacother 39: 1737-1740.

25. Schwalm JD, Lee CH (2003) "Acute Hepatitis Associ-ated with Oral Levofloxacin Therapy in a Hemodialysis Patient”, Canadian Medical Association Journal 168: 847-848 